\title{
Correction to: "Generalist" Journals between Dissemination of Economics and Regime Propaganda
}

\author{
Francesca Dal Degan and Fabrizio Simon
}

Correction to:

Chapter "Generalist" Journals between Dissemination of Economics and Regime Propaganda in:

M. M. Augello et al. (eds.),

An Institutional History of Italian Economics

in the Interwar Period-Volume I, Palgrave Studies

in the History of Economic Thought,

https://doi.org/10.1007/978-3-030-32980-8_6

In the original version of the chapter "'Generalist" Journals between Dissemination of Economics and Regime Propaganda the incorrect author given name (Francesca Dal) and family name (Degan), which has now been corrected. The chapter has been updated with the necessary change.

The updated version of this chapter can be found at https://doi.org/10.1007/978-3-030-32980-8_6 